Artículos 



\title{
FUNCIONAMIENTO Y EFICACIA PROBATORIA DE LOS INDICIOS EN EL PROCESO PENAL ACUSATORIO
}

\author{
Performance and efficiency evidentiary of the indications in the \\ process criminal accusatory
}

Ramón Porfirio ACUÑ ${ }^{1}$

\begin{abstract}
Sumario:
I. Introducción. II. Breve noción histórica. III. La evolución Argentina. VI. Visión conceptual. V. Indicio o prueba indiciaria. VI. Indicios o presunciones. VII. Las presunciones y el Derecho penal. VIII. Naturaleza jurídica. IX. Clasificación de los indicios. X. Regulación normativa. XI. Sistema de valoración. XII. Los estados conviccionales. XIII. Eficacia probatoria de los indicios. XIV. Los alcances de la eficacia. XV. Conclusiones.
\end{abstract}

Resumen: El presente trabajo tiene por objeto analizar el funcionamiento de los indicios en el sistema de enjuiciamiento penal, en base al tratamiento formulado por la doctrina $y$ jurisprudencia nacional, provincial y del derecho comparado, a los fines de intentar a modo de aproximación, una conclusión sobre la eficacias confirmatoria en las distintas etapas del proceso penal acusatorio,

Palabras clave: Prueba Indiciaria. Funcionamiento de los indicios. Eficacia de los indicios. Indicios y Proceso Penal Acusatorio.

Abstract: This study aims to analyze the functioning of the signs in the system of criminal prosecution, based on the treatment formulated by doctrine and jurisprudence, provincial, national and comparative law, for the purpose of attempting to approach, a conclusion about the efficiencies as a confirmatory in the various stages of the adversarial criminal proceedings.

Key words: Circunstantial evidence. Functioning of the signs. Effectiveness of the signs. Circunstancial criminal accusation process.

\section{INTRODUCCIÓN}

La problemática de la prueba judicial constituye sin dudas, una cuestión medular y de superlativa relevancia en el proceso penal, no sólo desde la perspectiva teórica dogmática, sino también desde la praxis forense. Las complejidades surgen de los medios probatorios

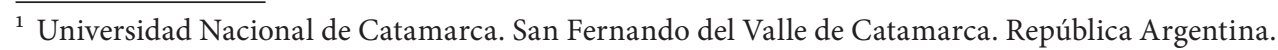


admitidos por el sistema, esto es, la prueba común o directa propiamente dicha, en sentido estricto, como así también de otros componentes y fenómenos jurídicos que integran la constelación confirmatoria del proceso penal. En tal horizonte emerge con luz propia y trascendencia procesal la temática relativa a los indicios, su funcionamiento y eficacia probatoria en el proceso penal acusatorio, cuyo abordaje particular, será el objeto de este trabajo.

La doctrina en general, denomina prueba directa a la prueba propiamente dicha, en tanto a los indicios, le asigna la denominación de prueba indirecta o indiciaria, entre otras denominaciones.

Históricamente, en el derecho romano, el indicio era el resultado, de cuya raíz surge la teoría de la prueba indiciaria como fruto de una elaboración doctrinal y jurisprudencial, cuyo origen proviene del derecho romano justinianeo.

La etimología de la palabra o término indicio es análogo a la inducción, en lugar de referirse a la idea, se hace referencia a la proposición material, sustituyendo al inde duco y el inde dico. ${ }^{2}$

En dicho contexto, la cuestión relativa al funcionamiento de los indicios en el enjuiciamiento penal, importa abordar una interesante temática de carácter procesal, cuyos aspectos esenciales y demás precisiones respecto a su dinámica y funcionamiento, obliga un recorrido sobre el tratamiento formulado por la doctrina y jurisprudencia nacional y del derecho comparado, a los fines de intentar a modo de aproximación, una conclusión sobre la eficacia confirmatorias de los indicios en las distintas etapas del proceso penal acusatorio.

En tal sentido, corresponde destacar que la referida aproximación tendrá como marco, el paradigma constitucional del debido proceso legal en la Argentina, cuya matriz acusatoria y democrática cobra protagonismo y vigencia a partir del proyecto de Código Procesal Penal de la Nación de 1986 de Julio Maier; $;$ la reforma constitucional de $1994 ;{ }^{4}$ el movimiento de reforma que a lo largo y ancho del país marcó el impulso de las tendencias que conforman los ejes sistémicos del diseño constitucional, con resultados tangibles en la actualidad, en razón de la actual vigencia de numerosos códigos procesales provinciales en la misma sintonía, y particularmente con relevancia superlativa, la vigencia del juicio por jurados en las provincias de Córdoba, ${ }^{5}$ Neuquén y Buenos Aires, ${ }^{6}$ y con diseños similares aprobados en las provincias del Chaco y Rio Negro, y por último, el reciente Código Procesal Penal de la Nación, Ley 27.063, que establece por primera vez, en el orden nacional, un modelo acusatorio y adversarial definido, quebrando definitivamente la resistencia inquisitorial de la jurisdicción nacional.

\footnotetext{
${ }^{2}$ HERNÁNDEZ ELVIRA, María Jesús, La prueba indiciaria en el proceso penal, Jueza en la Comunidad Autónoma de Canarias, www.icalanzarote.com/ Octubre 2010.

3 MAIER, Julio B,J, Proyecto de Código Procesal Penal de la Nación, Doctrina Penal, Depalma, Argentina, 1987.

${ }^{4}$ LEDESMA, Ángela Ester, La reforma procesal penal, Nova Tesis, Argentina, 2005.

5 CAFFERATA NORES, José I, Código Procesal Penal de la Provincia de Córdoba, Marcos Lerner, Argentina, 1992.

${ }^{6}$ GRANILLO FERNANDEZ, Héctor M, Juicio por jurados, Rubinzal Culzoni, Editores, Argentina, 2013. 


\section{BREVE NOCIÓN HISTÓRICA}

Los autores que han indagado en el plano histórico, sostienen que la técnica de los indicios ha sobrevivido a los diferentes sistemas procesales hasta nuestros días, destacando evidencias de intentos de sustitución de la prueba indiciaria que finamente fracasaron.

Hernández Elvira ${ }^{7}$ formula una clasificación de los periodos históricos de los indicios del siguiente modo:

$\left.1^{\circ}\right)$ La aplicación de los indicios surgió en el terreno de la retórica forense; $2^{\circ}$ ) En el Derecho Romano Clásico no existió una teoría general de los indicios; $3^{\circ}$ ) El indicio y las circunstancias indiciarias en el primitivo derecho romano se comprendían en tema de prueba; $4^{\circ}$ ) No obstante, la palabra indicio en su acepción moderna, solo se reconoce indiciariamente en las constituciones imperiales; $5^{\circ}$ ) Los indicios en el derecho postclásico y justinianeo pueden subsanar y suplir la falta de prueba representativas (testigos y documentos), ya que trata de indiciis ad probationem indubitatis et luce clarioribus expeditat; $6^{\circ}$ ) Las fuentes jurídicas romanas no reflejan los requisitos exigidos, para los indicios, sino la certeza, enfáticamente expresada "indicia indubitata et clariora luce expedita.[...]

La autora citada, señala que también subsistió incluso potenciada y alcanzó plena autonomía la prueba de indicios en el derecho intermedio, durante la vigencia del sistema de prueba legal, que preceptuaba que el Juez tenía que decidir iuxta alegata el probata y no secumdum conscientiam.

En este sistema, el Juez debía decidir, en relación con varios elementos probatorios, de acuerdo con el criterio apriorísticamente fijado por el legislador; que obligaba imperativamente al Juez a pronunciarse en un determinado sentido, aunque él estuviese convencido íntimamente de lo contrario. En tal sentido, tanto la ley como la doctrina en relación con determinados elementos de prueba, obligaban al Juez a limitarse a realizar una operación mecánica de los indicios, proliferando minuciosas clasificaciones probatorias y tablas de indicios. Los indicios, en sentido técnico, fueron considerados como elementos de prueba inferiores a la prueba representativa, pues le asignaban el valor de semiplena prueba.

Como se sabe, el sistema inquisitorial estableció la irracionalidad y monstruosidad del sistema de pruebas legales que imponía al juez discernir antes determinados marcos probatorios, suficientes o insuficientes, condenando o absolviendo con independencia de su convicción, pues se trataba de una simple adecuación normativa cuasi matemática.

El impulso de la Ilustración generó un importante movimiento reformista que desterró definitivamente el sistema de prueba legal o tasada, propiciando el sistema de libre convicción, que la revolución tomó como bandera, como método de valoración de las pruebas

\footnotetext{
7 HERNÁNDEZ ELVIRA, María Jesús, Op. Cit., nota 2, p. 1.
} 
adoptado por el Código Francés de Instrucción Criminal de 1808, producto de la codificación napoleónica, cuya influencia marcó un camino irreversible en toda Europa.

En la Argentina, el sistema de libre convicción fue adoptado en 1939, por el Código Procesal de Córdoba, que introduce la oralidad del juicio y la clara separación entre acusación y jurisdicción, al cual se sumaron varias provincias.

El sistema de prueba legal se mantuvo en la jurisdicción nacional y federal hasta el año 1992, fecha en la cual se deroga el Código de Procedimiento Penal de la Nación, escrito y de neto corte inquisitivo.

\section{LA EVOLUCIÓN ARGENTINA}

El Código de Instrucción Criminal Francés de 1808, mencionado precedentemente, recepta los caracteres del sistema inquisitivo y algunos aspectos del sistema acusatorio, al cual Julio Maier ${ }^{8}$ denomina Proceso Inquisitivo reformado.

La conquista española del continente americano (1492) impuso el sistema inquisitivo, con la vigencia de la Recopilación de Indias, Ordenamiento de Alcalá, Nueva y Novísima Recopilación y Siete Partidas, cuya estructura institucional desconocía la división de poderes, siendo la justicia una rama del gobierno derivada de la voluntad del rey, ${ }^{9}$ con los siguientes caracteres: predominio de la iglesia, carencia de principio de legalidad sustantiva y de separación de poderes, derivación monárquica, predominio de la investigación, ausencia de debate, limitación de la defensa, secreto y escrito, arbitrio judicial y crueldad de las penas. ${ }^{10}$

La independencia iniciada en la Argentina, a partir de 1810, y lograda definitivamente en 1816, no interrumpió la vigencia del sistema inquisitivo heredado de la Corona Española, cuya vigencia se extendió hasta 1992, cuando se deroga el Código Procesal de la Nación, que establecía el sistema de pruebas tasadas, los indicios y presunciones con valor de plena prueba.

En la Constitución Nacional de 1853, los constituyentes se apartan del modelo de Europa continental adoptando el diseño anglosajón, de carácter republicano y acusatorio, con las garantías de seguridad individual y juicio público por jurado, previsión constitucional que constituye un mandato incumplido en el orden nacional y federal, a excepción de las provincias de Córdoba, Neuquén, Buenos Aires, Chaco y Rio Negro, que receptaron el juicio por jurado, aunque el nuevo Código Procesal Penal de la Nación, Ley 27.063, prevé en su art. $23^{\circ}$, la implementación del Juicio por Jurados, según la ley especial que se dicte al efecto.

En 1889, se aprueba como Código de Procedimiento en Materia Penal para el Fuero Federal y los Tribunales Ordinarios de la Capital Federal y los Territorios Nacionales, reiterando un sistema de neto corte inquisitivo, cuya vigencia perduró hasta 1992, es decir, más de un siglo de vigencia.

Por su parte las provincias argentinas, inician un camino superador al régimen federal, y es Tomás Jofré, quién impulsa por primera vez (1915) el primer intento serio de avance ins-

\footnotetext{
${ }^{8}$ MAIER, Julio B. J. Proyecto de Código Procesal Penal de la Nación... Op. Cit., nota 3, p. 2.

${ }^{9}$ Idem.

${ }^{10}$ VÁSQUEZ ROSSI, Jorge, E. Derecho procesal penal, tomo I, Editorial Rubinzal-Culzoni, Argentina, 1995, p. 187-188.
} 
titucional, para las provincias de Buenos Aires y San Luis, aunque también con resultados negativos.

En 1939, la Provincia de Córdoba, de la mano de Alfredo Vélez Mariconde y la Escuela Cordobesa, toman las banderas de la oralidad en materia procesal del país y Latinoamérica, sancionando el Código Procesal Penal de Córdoba, adoptando el sistema mixto y oral teniendo como fuente el Código Italiano de 1930.

Varias fueron las provincias argentinas que adoptaron idéntico diseño, Santiago del Estero, San Luis, La Rioja, Jujuy, Mendoza, Salta, Catamarca, La Pampa, Corrientes, Chaco y Entre Ríos, incluida la República de Costa Rica.

El Proyecto Maier, de 1986, nacido al impulso de la novel democracia recuperada, significó el intento más acabado de lo que debiera ser el debido proceso penal para esa época, según los postulados de la Constitución Nacional. La propuesta del Código Procesal Penal Modelo para Iberoamérica, ${ }^{11}$ se habría concretado en un proyecto innovador, precisamente de la mano de unos de sus redactores, Julio B. Maier.

El Proyecto Levene, de 1987, sancionado finalmente como Código Procesal Penal de la Nación, Ley No 23.984, en 1990, constituyó una reiteración de los Código Provinciales de Rio Negro, Neuquén, Formosa, Chubut y Misiones, proyectados por el Prof. Ricardo Levene y de aquel proyecto de 1975, presentado al Senado de la Nación por José H. Martiarena y Alfredo L. Benítez, siguiendo en sus líneas centrales el Código de Córdoba de 1939, al cual Julio Maier le reconoció constituir un importante avance.

Pasando en blanco la evolución histórica antes referenciada, resulta fácil advertir dos caminos o carriles históricos distintos, respecto al funcionamiento de los indicios y sistema de valoración de la prueba.

En el fuero federal, desde la colonización española hasta el año 1992, funcionó la vigencia de un régimen procesal escrito y de carácter inquisitivo, con un sistema de pruebas tasadas y la recepción de indicios, como medio de prueba y con valor de plena prueba.

En el fuero ordinario provincial, a partir de 1940, la provincia de Córdoba adopta un sistema mixto, oral, con libertad probatoria y el sistema de sana critica racional o libre convicción, al cual adhieren con posterioridad y de manera progresiva la mayoría de las provincias argentinas.

Con posterioridad, de 1992, al derogarse el viejo código nacional de tinte inquisitivo, se adopta como nuevo Código Procesal Penal de la Nación, un diseño similar al Código Procesal Penal de Córdoba, vigente hasta el día de la fecha, no obstante la sanción del nuevo Código Procesal Penal de la Nación, ley 27.063, ${ }^{12}$ cuya vigencia ha sido prorrogada.

\section{VISIÓN CONCEPTUAL}

Muchos son los autores de la especialidad procesal que formularon definiciones conceptuales respecto de la figura de los indicios, algunas coinciden en sus aspectos centrales, otras en cambio, con visiones y perspectivas distintas, exhiben nuevos matices y elementos del instituto que tratamos.

\footnotetext{
${ }^{11}$ Código Procesal Penal Modelo para Iberoamérica: Autores: Vélez Mariconde, Clariá Olmedo y Fernando de la Rúa; en un segundo momento: Fernando de la Rúa, Fairen Guillén y Julio Maier, luego se agregaron Ada Pellegrini Grinover y Jaime Bernal Cuellar. Concluido en 1988, en la Reunión del Instituto Iberoamericano de Derecho Procesal en Rio de Janeiro-Brasil.

${ }^{12}$ Sanción: 04/12/2014; Decreto 2321, Promulgación 09/12/2014 y Publicación 10/12/2014.
} 
Así, Julio Maier ${ }^{13}$ señala:

El indicio no es más que una conjetura, una inferencia: de un hecho que se conoce, pero que no constituye el objeto de prueba, se infiere otro mediante una operación mental silogística o próxima a ello que permite afirmarlo al menos de modo probable. Los indicios no son medios de pruebas, sino, tan solo, una aplicación del razonamiento humano inductivo-deductivo que, a partir de un hecho considerado como cierto, arriba a una segunda afirmación a través de una regla de cualquier tipo (científica, técnica, artística o de la experiencia) [...]

En línea similar se enrola Cafferata Nores, ${ }^{14}$ dice:

El Indicio es un hecho (o circunstancia) del cual se puede, mediante una operación lógica, inferir la existencia de otro. Según su nombre mismo lo expresa (índex), el indicio es, por decirlo así, el dedo que señala un objeto. Su fuerza probatoria reside en el grado de necesidad de la relación que revela entre en hecho conocido (el indiciario), psíquico o físico, debidamente acreditado, y otro hecho desconocido (el indicado) cuya presencia se pretende demostrar. La naturaleza probatoria del indicio no está in re ipsa, sino que surge como el fruto lógico de su relación con una determinada norma de experiencia, en virtud de un mecanismo silogístico, en el cual el hecho indiciario se toma como premisa menor, y una enunciación basada en la experiencia común funciona como premisa mayor. La conclusión que surge de la relación entre ambas premisas es la que otorga fuerza probatoria al indicio. [...]

Jauchen, ${ }^{15}$ en cambio, expresa:

El indicio conceptualmente no es otra cosa que lo que modernamente se considera elemento de prueba, es decir, todo dato o circunstancia debidamente comprobada en la causa por vía de un medio de prueba. El dato surgirá así de los dichos del testigo, del contenido de una declaración del imputado, de un dictamen pericial, de una inspección judicial o cualquier otro medio. Luego, dicho dato constituye un elemento probatorio del cual el juzgador mediante un razonamiento lógico, puede inferir otro hecho desconocido; es la operación mental por medio de la cual se toma conocimiento de un hecho desconocido por inferencia que sugiere el conocimiento de un elemento comprobado. Este elemento comprobado es un indicio, no un medio de prueba en el sentido técnico de este último. [...]

Clariá Olmedo, ${ }^{16}$ a su vez, se expide: el indicio es el objeto o circunstancia probados que permiten formular un argumento capaz de llevarnos a la prueba de otro hecho. De aquí que parezca más correcto decir que es indirecta la prueba que tiene por objeto un indicio. Por eso se llama también prueba indiciaria, que es fuente de las presunciones hominis. [...]

\footnotetext{
${ }_{13}^{13}$ MAIER, Julio B, J, Derecho procesal penal, Editores del Puerto 2011, Argentina, t. III, p. 179/182

${ }^{14}$ CAFFERATA NORES, José, La prueba en el proceso penal, Depalma, Argentina, 1988, p. 202/208.

${ }^{15}$ JAUCHEN, Eduardo M, Tratado de la prueba en materia penal, Buenos Aires, Argentina, Rubinzal-Culzoni, 2002, pp. 583-584.

${ }^{16}$ CLARIA OLMEDO, Jorge A., Tratado de Derecho procesal penal, Rubinzal Culzoni, Argentina, 2009, tomo V, p. 34
} 
Devis Echandía, ${ }^{17}$ manifiesta:

El indicio es el hecho conocido, del cual se obtiene, mediante una operación lógica-crítica, un argumento probatorio que permite inducir de aquel, otro hecho desconocido, la presunción judicial o de hombre es un principio lógico, basado en las máximas generales de la experiencia o en conocimiento especializados (que suministran los peritos) que le sirve al juez para determinar el valor probatorio del indicio o de otra prueba cualquiera. El indicio es la prueba y la presunción judicial es la consecuencia de la regla de experiencia o técnica que permite valorarla y que no es prueba, ni objeto de prueba. [...]

Manzini, ${ }^{18}$ sostiene que el indicio es una circunstancia cierta de la que se puede sacar por inducción lógica, una conclusión acerca de la existencia o inexistencia de un hecho a probar. $[\ldots]$

Alvarado Velloso, ${ }^{19}$ dice:

Denominase indicio a un hecho conocido (el indiciario o el indicador) a partir del cual se razona -por inducción, deducción o abducción crítica- la existencia de un hecho desconocido (el indicado). Constituye, por ende, un medio de confirmación indirecto que le permite al juez obtener el resultado de una presunción que, a su turno, es el juicio lógico que permite al juzgador tener como cierto o probable un hecho incierto después de razonar a partir de otro hecho cierto. [...]

Mittermaier, ${ }^{20}$ sostiene que un indicio es un hecho que está en relación tan íntima con otro hecho, que un juez llega del uno al otro por medio de una conclusión muy natural. [...]

Oderigo, ${ }^{21}$ define al indicio, como la circunstancia o antecedente que autoriza a fundar una opinión sobre la existencia del hecho. En tanto la presunción, es el efecto que esa circunstancia o antecedente produce en el ánimo del juez sobre la existencia del hecho, mediando por lo tanto, entre ellos, una relación de causa a efecto. [...]

Arocena, y otros, ${ }^{22}$ opinan:

El indicio es un elemento de prueba funcionalmente entendido, que se emplea de manera individual o colectiva (junto a otros datos) y al que se le aplica un razonamiento inductivo o histórico, a fin de concluir en la probable existencia o inexistencia de alguno o todos los elementos que componen los extremos objetivo y subjetivo de la imputación delictiva concreta. Se trata, pues, del dato objetivo que, introducido legalmente al proceso, produce un conocimiento que puede revestir distintos grados de probabilidad acerca de alguna circunstancia relevante para determinada

${ }_{17}^{17}$ DEVIS ECHANDIA, Hernando, Teoría general de la prueba judicial, p. 72 y ss., Zavalia, Argentina, 1981, p. 72 y ss..

${ }^{18}$ MANZINI, Vicenzo, Tratado de Derecho procesal penal, t. III, p. 482, traducción española, Buenos Aires, Argentina, Ed. EJEA, 1952, t.III, p. 482.

${ }^{19}$ ALVARADO VELlOSO, Adolfo y ACUÑA, Ramón Porfirio, Lecciones de Derecho procesal, adaptado a la legislación procesal de la Provincia de Catamarca, Nuevo Enfoque Jurídico, Argentina, 2011, p. 545.

${ }^{20}$ MITTERMAIER, Karl, J. A., Tratado de la prueba en material criminal, trad. González del Alba, Madrid, Reus 1906, p. 355..

${ }^{21}$ ODERIGO, Mario A., Derecho procesal penal, Buenos Aires, Argentina, Ed. Depalma, 1973, t. I, p. 103.

22 AROCENA, Gustavo y otros, Prueba en materia penal, Astrea, Argentina, 2009, p. 457 y ss. 
causa penal. En otras palabras, y como asevera Volk, bien mirada toda prueba es un indicio que aún en el mejor de los casos no supera una probabilidad. [...]

Chaia, ${ }^{23}$ argumenta:

Un indicio es un hecho cierto que en relación íntima con otro hecho al que el juez llega por medio de una conclusión natural o inferencia, de allí que se lo considere una prueba critica, circunstancia o indirecta distinta de las pruebas histórica, personal y directa. El indicio es vital a la hora de tomar una decisión, pues apuntala el pensamiento del juzgador, le indica el camino a seguir; indicere. Los indicios no surgen de medios de pruebas distintos a los conocidos, sino que provienen de ellos, de cualquier elemento de prueba que apunte, describa o ayude a descubrir el hecho investigado. Así, el indicio se forma a partir de todo elemento probatorio que cumpla la función de indicar el camino, de alumbrar la oscuridad de un hecho, de darle luz al saber judicial. De este modo, puede resultar de una pericia, de un rastro de sangre, de un testimonio, de una prueba de ADN. Es posible entonces, definirlo como un elemento distinto al delito, pero que puede revelarlo o indicar aspectos de él. [...]

Hernández Elvira, ${ }^{24}$ explica:

La prueba indiciaria ha sido relevante y está admitida por el ordenamiento jurídico procesal español, según reconoce reiterada doctrina jurisprudencial. En tal sentido, señala que en realidad, los indicios, técnicamente, no constituyen un verdadero medio de prueba, sino una labor lógicojurídica del juez, que le permite, estando probado o conocido un hecho, llegar a establecer la existencia de otro, que es el relevante para el proceso y la Sentencia, puesto que es el hecho punible e incriminado, tipificado en la Ley Penal. [...]

Zwanck, ${ }^{25}$ se expide señalando que el indicio expresa más bien la cosa que sirve de signo; la circunstancia del hecho en que se basa la inferencia: y que la presunción se refiere a la relación lógica, agregando que los civilistas hablan de presunciones, en tanto los penalistas, de indicios. [...]

En nuestra opinión, sin perjuicio de las valiosas definiciones conceptuales de los autores antes referenciados, y a los fines de una mejor comprensión del mecanismo externo-interno de la construcción indiciaria, intentaremos esquematizar los distintos momentos y los elementos que conjugan en el referido circuito:

a) El hecho conocido: Se trata de presupuesto inicial de la construcción indiciaria, plataforma fáctica conocida de la cual se parte, para construir la inferencia, enlace, vinculación o tracto, con el extremo factico e hipotético a conocer. ${ }^{26}$

Si bien es cierto, puede ser un hecho probado o acreditado a través de los medios de pruebas típicos regulados por la ley, ello no excluye la hipótesis de cualquier otro dato o

${ }^{23}$ CHAIA, Rubén A, La prueba en el proceso penal, p. 650 y ss., Hammurabi, Argentina 2010, p. 650 y ss.

${ }^{24}$ HERNÁNDEZ ELVIRA, María Jesús, Op. Cit, nota 2, p. 1.

${ }^{25}$ ZWANCK, Carlos A., Indicios, en la Enciclopedia Jurídica Omeba, t. XV, p. 487.

${ }^{26}$ La doctrina le asigna distintas denominaciones: hecho conocido, circunstancia, cosa que sirve de signo, dato objetivo, antecedente, hecho indiciario o indicador, objeto o circunstancia probado, etc. 
información que no tenga esa calidad, que hubiere ingresado al proceso, ${ }^{27} \mathrm{u}$ otros datos externo al proceso, como son los hechos notorios que supone un hecho conocido por todos, sin necesidad de probar.

En tal sentido, cualquier hecho, circunstancia, dato o información que ingresa al proceso, genera naturalmente reflejos o destellos indiciarios en direcciones opuestas o similares, es decir en sentido positivo o negativo, respecto a distinto hechos, vinculados o no al proceso. El análisis del dato inicial, tiene un primario y preciso objetivo, la vinculación, enlace o inferencia en relación al extremo fáctico a conocer, cual si fuera el hilo conductor o punta de la madeja.

b) El enlace o inferencia: Se trata de una construcción mental o razonamiento crítico, mediante el cual se procede al enlace o inferencia con el hecho a conocer, a los fines de precisar su existencia. Dicho enlace o conexión, como conjetura crítica, se traduce en la integración de las partículas indiciarias, que son fragmentarias, incompletas e insuficientes, como lo señala Falcón, ${ }^{28}$ para conformar un conjunto, un todo uniforme y en la misma dirección que permita la conexión o vinculación con el hecho a conocer, teniendo como base las reglas de la experiencia, conocimientos técnicos, o científicos.

En tal sentido, Jauchen, ${ }^{29}$ al preguntarse cuándo es necesaria una inferencia indiciaria, se contesta:

Cuando varios indicios se relacionan con una sola causa, su concurso importa una prueba indiciaria necesaria, pues señala de tal forma, necesariamente, al hecho delictivo, a su autor o a ambos. En este supuesto la prueba indiciaria es perfecta. Si bien los indicios aislados son meramente contingentes, cuando ellos son varios, diferentes y concordantes, adquieren la cualidad de necesarios suministrando una prueba altamente acreditativa. (...)

c) El hecho incierto a conocer: El hecho incierto a conocer, constituye el objetivo o el puerto final de la construcción mental crítica del juzgador, quien luego de integrar los hechos o datos indiciarios, establece el vínculo o conexión con el hecho a conocer o indicado, afirmando su existencia y agotando el circuito de la construcción indiciaria.

d) Valoración: La valoración de los indicios, a nuestro juicio, tiene dos momentos: El primero, de carácter individual y necesario, vinculado a su existencia misma, esto es la construcción de la conexión o inferencia con el hecho a conocer, apriorística y limitada a la existencia o inexistencia del hecho indicado, como consecuencia de una pre-valoración de la entidad y significación de las piezas indiciarias que fueron reflejados por el hecho conocido.

El segundo momento, de carácter eventual y general, pues se verifica cuando se logra conocer la existencia del hecho indicado y éste pasa a ser valorado con el resto de los medios confirmatorios que integran el proceso, en relación a su objeto principal o cuestiones incidentales del mismo. Resulta eventual, pues sólo en el caso de haber alcanzado la inferencia o

\footnotetext{
${ }^{27}$ FALCON, Enrique M, Lógica y justificación del razonamiento probatorio, dice: rastros, huellas, vestigios y circunstancias en La prueba en el proceso judicial, Asociación Argentina de Derecho Procesal, Rubinzal Culzoni, Argentina, 2009, p. 122 y ss.

${ }^{28}$ Ídem.

29 JAUCHEN, Eduardo M., Op. Cit, nota 15, p. 10.
} 
conexión con el hecho a conocer, será valorado en el marco del proceso, caso contrario, si la inferencia es negativa, desaparece toda posibilidad del indicio intentado.

Para algunos autores, ${ }^{30}$ los indicios, en el mejor de los casos, sólo alcanza para construir una convicción probable, sobre algunas cuestiones puntuales del proceso, no sobre el objeto del mismo.

En sentido opuesto, dice Jauchen: ${ }^{31}$

Todo indicio que permite mediante la lógica y la experiencia una inferencia con relación al hecho delictivo, tanto más relevante será cuando mayor sea la aproximación que permita tener con el mismo. Dentro de la amplia gama de circunstancias que es menester acreditar, para poder efectuar una acusación y luego la certeza para una condena, en relación a la existencia de un delito y a la participación en él del imputado, su intervención en el hecho es naturalmente la más importante y necesaria. Sin perjuicio, de todos los medios probatorios, este extremo también puede acreditarse mediante elementos indiciarios, aun cuando desde ya cabe poner el acento en que en este caso será preciso: un celo y exigencia mayor que respecto a otras circunstancias, debiendo los indicios ser necesariamente infalibles e irrefutables para sustentar una certeza al respecto.(...)

\section{INDICIO O PRUEBA INDICIARIA}

Algunos autores ${ }^{32}$ formulan un distingo entre indicio y prueba indiciaria, sobre todo aquel sector de la doctrina que sostiene que los indicios constituye un medio de prueba. En tal sentido, se afirma que el indicio, si bien es cierto constituye fuente de prueba, todavía no es medio de prueba. Para que ello acontezca, es necesario que este sea sometido a un raciocinio inferencial, que permita llegar a una conclusión y que ella aporte conocimientos sobre el objeto de la prueba, y a partir de allí se puede hablar de prueba indiciaria.

En la misma dirección, se afirma que indicio y prueba indiciaria no son idénticos, porque muchas veces ocurre la creencia errónea de que la prueba indiciaria es solamente una sospecha de carácter meramente subjetivo, intuitivo, o que la prueba indiciaria se inicia y se agota en el indicio.

Otros autores, señalan que la diferencia entre indicio y prueba indiciaria es ineludible, pues entienden que prueba indiciaria (o prueba por indicios)es un concepto jurídico-procesal compuesto y, como tal, incluye como componentes varios subconceptos: indicio (dato indiciario), inferencia aplicable y la conclusión inferida (llamada, aun por muchos, presunción del juez o presunción del hombre), que conducen al descubrimiento razonado de aquello que es indicado por el indicio (el conocimiento que se adquiere sobre lo que tradicionalmente se conoce como hecho indicado o dato indicado).

De la conclusión obtenida del razonamiento correcto es además conducente, pertinente y útil, se convertirá en argumento probatorio; de manera que como se verá, el indicio es téc-

\footnotetext{
${ }^{30}$ AROCENA, Gustavo, y otros, Op. Cit, nota 23, p ,11.; y MAIER, Julio B, Op. Cit., nota 13, p, 9.

${ }^{31}$ JAUCHEN, Eduardo M.; Op. Cit., nota 15, p. 10.

32 DELLEPIANE, Antonio, La nueva teoría de la prueba, Bogotá: Temis, 1994, p. 57; MIXÁN MASS, Florencio, La prueba indiciaria, Trujillo: BLG, 1992, p. 10; y ROSAS YATACO, Jorge; Prueba indiciaria: Doctrina y jurisprudencia nacional. Anuario de Derecho penal 2004. La Reforma del proceso penal peruano, pp. 291-292. 
nicamente el primer subconcepto, el primer componente del concepto de prueba indiciaria. Ello, lógicamente no descarta la vinculación que existe entre ambos conceptos.

En nuestra opinión, el distingo entre indicios y prueba indiciaria carece de interés, por cuanto en la realidad y por imperio de una larga y consagrada praxis judicial, la utilización de ambos conceptos es indistinta, con significados equivalentes o como conceptos sinónimos.

Por otra parte, las diferencias formulada por los autores citados, tienen que ver naturalmente con los posicionamientos adoptados en su oportunidad, a la hora de expedirse con relación a la naturaleza jurídica de los indicios.

\section{INDICIOS Y PRESUNCIONES}

Tanto la doctrina procesal penal y procesal civil, no tiene un criterio unánime, a la hora de distinguir entre indicios y presunciones, toda vez que para algunos son conceptos equivalentes, en tanto para otros, son diametralmente distintos.

\section{Enseña Maier: $:^{33}$}

La llamada presunción -voz que en ocasiones es utilizada como sinónimo de indicio- si la palabra se utiliza con propiedad, es un indicio legal; conforme a una regla jurídica, de un hecho se infiere otro como cierto. Algunos creen que el indicio en determinadas condiciones engendra la presunción que se trata de conceptos vinculados entre sí por una relación causal, en definitiva que la presunción es la conclusión del indicio. (D’Albora) [...]

Ese, si bien no es un uso lingüístico y semántico inadecuado de la palabra, no coincide con el significado técnico jurídico, pues la presunción revela una idéntica operación lógica que la explicada para el indicio, sólo que, en ella, la regla según la cual arribamos a determinada conclusión está representada por una norma jurídica, con pretensión de ser aplicada como obligatoria. De modo general, estas presunciones son calificadas como juri et de jure, cuando no admiten prueba en contrario, o juris tantum, cuando la admiten para determinar su falta de aplicación (negación de la conclusión) No vale la pena citar ejemplos, pues, en materia penal, únicamente son concebibles las ultimas, y ello tan sólo en tanta sean reglas racionales, que no lesionen principios fundamentales o básicos del Estado de Derecho. A la ley penal le ha resultado fácil transformar indicios en presunciones, que incluso no admite prueba en contrario, frente a las dificultades que presenta el procedimiento probatorio dentro del procedimiento judicial. [...]

Zwanck, ${ }^{34}$ expresa:

No se ha logrado hasta el presente con relación a los indicios, una denominación bien precisa. Agrega que los civilistas hablan con preferencia de presunciones; los criminalistas de indicios, y los juristas ingleses o americanos de circunstancias, que es el término más genérico: y consideran, por su parte, que el indicio expresa más bien la cosa que sirve de signo; la circunstancia o el hecho en que se basa la inferencia: y que la presunción se refiere a la relación lógica. [...]

\footnotetext{
${ }^{33}$ MAIER, Julio B, Op. Cit., nota 13, p. 9.

34 ZWANCK, Carlos A., Op. Cit., nota 25, p. 12.
} 
Oderigo, ${ }^{35}$ dice: Ambos corresponden a conceptos distintos. Indicio es la circunstancia o antecedente que autoriza a fundar una opinión sobre la existencia del hecho. Presunción es el efecto que esa circunstancia o antecedente produce en el ánimo del juez sobre la existencia del hecho. Mediando por lo tanto, entre ellos, una relación de causa a efecto. [...]

En nuestra opinión, en la actualidad el tema ha perdido actualidad y vigencia. Para los nuevos sistemas procesales que adoptaron los principios del acusatorio, no existe discusión sobre el punto, pues admiten la autonomía funcional de ambos concepto en el marco probatorio. A los indicios como elementos de prueba o prueba indirecta, producto de una elaboración mental; en tanto a las presunciones como producto de una norma jurídica de carácter obligatoria.

\section{LAS PRESUNCIONES Y EL DERECHO PENAL}

En relación a la construcción normativa de las presunciones en el derecho penal moderno, Julio Maier ${ }^{36}$ formula una profunda crítica respecto del avance inusitado del neopunitivismo, contrariando sensiblemente las bases de la garantía establecida por el derecho penal del acto.

En tal sentido, critica:

A la ley penal le ha resultado fácil transformar indicios en presunciones, que incluso no admite prueba en contrario, frente a las dificultades que presenta el procedimiento probatorio dentro del procedimiento judicial. Ya históricamente ello sucedió a través de la poena extraordinaria o de las penas de sospecha, que permitían la punibilidad sin rigor probatorio. Hoy ello ocurre por intermedio de los delitos de peligro abstractos, que punen el hecho antecedente del cual surge el indicio (peligro) determinante de la probabilidad del riesgo para el bien jurídico a proteger. O los llamados delitos de anticipación, que regularmente ingresan la punición al ámbito de los actos preparatorios. A ello se dedica el derecho penal moderno (o mejor calificado, de la posmodernidad), en su ambición por dominar el futuro, el riesgo -en una sociedad en la que el propio ser humano ha multiplicado geométricamente los riesgos, por eso llamada sociedad del riesgo-, con abandono del derecho penal del acto, referido al pasado, que solo esperaba retribuir con el castigo la culpabilidad de alguien que había dañado algo valioso. En esos delitos, que hoy ya no representan una excepción, sino, antes bien, el núcleo vigoroso y creciente del Derecho Penal expansivo o de la inflación punitiva (panpunitivismo, neopunitivismo o, más literariamente, fascinación ante el Derecho Penal) protector de bienes jurídicos supra individuales -siempre valores de la acción administrativa del Estado en consecución o protección del bien común-, las presunciones de daño, aunque escondidas, constituyen la regla. [...]

\section{NATURALEZA JURÍDICA}

La naturaleza jurídica de los indicios, también ha generado visiones antagónicas en la doctrina, con un abanico de posicionamientos en punto a su denominación: a) medio de prueba; b) objeto de prueba; c) argumentos de prueba; d) fuente de deducción; d) medio de

\footnotetext{
35 ODERIGO, Mario, A., Op. Cit,. nota 21, p. 11.

${ }^{36}$ MAIER, Julio B, Op. Cit, nota 13, p. 9. 
confirmación indirecto o prueba indirecta; e) fuente de presunciones judiciales; f) elemento de prueba; etc.-

Clariá Olmedo ${ }^{37}$, desde el punto de vista del objeto, asigna a los indicios el carácter de prueba indirecta, la prueba del indicio: hecho indiciario que es fuente de las presunciones hominis. Para el maestro cordobés, el indicio y la presunción no son medios de prueba, sino que se proyectan al objeto. Funcionan como amalgamas de las pruebas para correlacionar con el razonamiento los objetos que hacen al hecho imputado.

En línea similar, Alvarado Velloso, sostiene que los indicios constituyen un medio de confirmación indirecto que le permite al juez obtener el resultado de una presunción que, a su turno, es el juicio lógico que permite al juzgador tener como cierto o probable un hecho incierto, después de razonar a partir de otro hecho cierto.

\section{Según explica Julio Maier: $:^{38}$}

Los indicios no son medios de pruebas, sino, tan solo, una aplicación del razonamiento humano inductivo-deductivo que, a partir de un hecho considerado como cierto, arriba a una segunda afirmación a través de una regla de cualquier tipo (científica, técnica, artística o de la experiencia) Precisamente por eso, ellos son los representantes de la llamada prueba indirecta según su objeto, en el sentido de que el tema a probar en ellos (objeto de prueba) no es un elemento de la imputación penal(objeto de proceso) sino un hecho circunstancia o característica ajena a ella, de la cual se infiere algún elemento del objeto del procedimiento (pertinencia del objeto de prueba con el objeto procesal).

En tesis contraria, Devis Echandía, ${ }^{39}$ quien considera que los indicios son un medio de prueba, al señalar: Compartimos el concepto de la mayoría de los autores, que reconocen a los indicios el carácter de medio de prueba En la misma dirección, Francisco D’Albora, quien ha caracterizado a los indicios como medio de prueba.

Florián y Schönke ${ }^{40}$ consideran que los indicios no son prueba, sino objeto de prueba, criterio que según Devis Echandía es errado, porque:

Aquellos contemplan el hecho en sí mismo, separado del argumento probatorio que de él obtiene el juez y que constituye su fuerza probatoria, y confunden la prueba del hecho indicador, que es necesaria siempre, con el indicio que este contiene y que constituye un medio autónomo de prueba. La circunstancia de que el hecho indiciario sea objeto de prueba, no excluye su condición de medio de prueba respecto al hecho indicado, de la misma manera como la confesión judicial y los testimonios o peritaciones producidas en otro proceso son medios autónomos de prueba, no obstante que también necesitan ser probados mediante testimonios o por las copias legalmente expedidas. Ese indicio probado por otros medios, es a su vez el vehículo o conducto que le suministra al juez los argumentos probatorios para formar su convencimiento sobre el hecho que se investiga. Es decir, lo indicios son una de las varias clases de prueba que deben ser probadas, a su vez, por otros medios"

${ }^{37}$ CLARIA OLMEDO, Jorge, Op. Cit., nota 16, p. 10.

${ }^{38}$ MAIER, Julio B, Op. Cit, nota 13, p. 10.

${ }^{39}$ DEVIS ECHANDÍA, Hernando, Op. Cit., nota 17, p. 10.

${ }^{40}$ Ídem. 
Kielmanovich, ${ }^{41}$ desde una perspectiva distinta, sostiene;

Las presunciones hominis“, son un medio de prueba critica que se sirve de la comprobación de ciertos y determinados hechos que no están constituidos por la representación de estos, a partir de los cuales se los deduce o induce mediante un argumento probatorio según normas de experiencias común o científica del magistrado. El hecho que se quiere probar, es decir el hecho de la prueba, no es conocido, pues a través de la percepción del juez, de las partes o de testigos, sino mediante su deducción a partir o derivada de un hecho previamente probado por prueba directa -no se puede extraer presunción de presunción- el hecho que sirva para la comprobación de aquel, vale decir el indicio, en tanto esa consecuencia aparezca naturalmente por obra de un juicio lógico"

Lequisamon, ${ }^{42}$ por su parte, se inclina por atribuir a los indicios el carácter de fuente de presunciones judiciales, ya que aquellos son los que dan sustento a éstas, constituyendo por ende su fuente.

Las distintas opiniones de los destacados autores y juristas mencionados precedentemente, en relación a la naturaleza jurídica de los indicios, refleja la riqueza procesal que exhibe el instituto cuyo tratamiento nos convoca en el presente trabajo, en base a lo cual podemos arribar a las siguientes conclusiones:

Los indicios no son medios de pruebas, ni prueba directa, sino un elemento de confirmación indirecto, que permite construir una convicción probable, sobre algunas cuestiones del proceso, no sobre el objeto del mismo.-

\section{CLASIFICACIÓN DE LOS INDICIOS}

Muchos son los autores que han formulado una clasificación de los indicios, como así también otros que entienden la inconveniencia de cualquier tipo de clasificación.

Leguizamón ${ }^{43}$ cita la clasificación de Gorphe, del siguiente modo:

a) Según su fuerza probatoria: manifiestos, aproximados o alejados, según tuviese con el hecho a probar, una relación directa casi necesaria, directa no necesaria o simplemente una relación contingente. b) Según su extensión, en comunes o generales y en propios o especiales, según se relacionasen con toda clase de delitos o, al contrario, con un delito en particular. c) En el plano cronológico, en antecedentes, concomitantes o subsecuentes, según la época en que se ubicaran en relación al delito.

A su turno, Devis Echandía, ${ }^{44}$ admite la imposibilidad de una clasificación comprensible de todos los indicios, dado su carácter ilimitado además de señalar que las clasificaciones son consideradas en la actualidad, artificiales e inútiles, en función de la libertad de juez para la apreciación de la fuerza probatoria, sin perjuicio de reconocer cierta utilidad práctica de algunas que se mencionan a continuación:

${ }^{41}$ KIELMANOVICH, Jorge L, Código Procesal Civil y Comercial de la Nación, Lexis Neris-Abeledo Perrot, Buenos Aires, Argentina, 2003, p. 78.

${ }^{42}$ LEGUIZAMÓN Héctor Eduardo, en Las presunciones judiciales y los indicios, Rubinzal Culzoni, Argentina 2006, p. 81.

${ }^{43}$ Ídem.

${ }^{44}$ DEVIS ECHANDIA, Hernando, Op. Cit., nota 17, p. 10. 
a)La de anteriores, concomitantes y posteriores al hecho desconocido que se trata de verificar; b) La de personales o subjetivas o materiales, según se refieran a condiciones y modo de ser de una persona (como la capacidad intelectual, física o moral para el acto delictivo o el hecho de significación civil) o cosas, huellas, rastros y similares; c) La de necesarios, según que uno solo baste para producir el convencimiento, en razón de que supone indispensablemente el hecho indicado, por corresponder a una ley física inmutable, de causalidad necesaria o contingente, si apenas constituye un inferencia de probabilidad, subdividiéndolos en graves y leves, inmediatos o próximos y mediatos o remotos, según su valor probatorio y la proximidad de la conexión entre los dos hechos; d) La de positivo o negativos, según concurran a indicar la existencia o inexistencia del hecho investigado o de la responsabilidad del sindicado o imputado; e) La de causales y de efectos, según que concurran al acaecimiento del hecho o signifiquen efectos del mismo; y f) La de comunes o genéricos y propios o específicos.

En España, ${ }^{45}$ la doctrina especializada clasifica los indicios, a los efectos de la valoración probatoria del siguiente modo: a) Indicios de capacidad física (aptitud física o psíquica del agente para la comisión del delito); b) Indicios de moral (propensión al delito del agente); c) Indicios de oportunidad(momento concreto, lugar, coparticipación); d) Indicios de manifestaciones (lo depuesto en un primer momento y a lo largo del procedimiento, contradicciones, etc.), e) Indicios del móvil, indicios de huellas materiales (objetos que se le encuentran al acusado como, armas, disfraces, o los provenientes de un delito contra la propiedad; instrumentos que aparecen en el lugar de comisión p.ej., huellas dactilares, semen, sangre...); d) Indicios del modus operandi, de tal suerte que, la reiteración de conductas delictivas de forma semejante y en concretos lugares, por parte de uno o varios sujetos, puede dar lugar a que la acreditación de la participación de todos o alguno de ellos en uno de los delitos, sirva de indicio de autoría para los restantes.

Otras clasificaciones ${ }^{46}$ refieren: Los indicios de presencia y participación en el delito, que también se pueden llamar de oportunidad física, o de oportunidad material en sentido estricto, obtenidos del importante hecho de que el individuo estuviera, sin razón plausible, en el lugar y al tiempo del delito. En sentido amplio, aquí se ubican indicios muy diversos, sacados de todo vestigio, objeto o circunstancias que implique un acto en relación con la perpetración del delito: señales de fractura o de sustracción, rastros de golpes o de polvo, manchas de sangre o barro, tenencia del instrumento del delito, descubrimiento de un objeto comprometedor en el lugar del hecho o en la casa del sospechoso. Ese hecho material resulta sospechoso, solo porque no tiene justificación o, más aún, porque el acusado lo explica mal.

Los Indicios provenientes de la personalidad, esta clase de indicios tienden a tomar en consideración la conducta anterior del sujeto y su personalidad a fin de inferir de ello si tiene capacidad delictiva que conduzca a presumir su autoría en el hecho que se investiga. En consecuencia, liminarmente es preciso hacer una importante aclaración respecto a que ello no importa adoptar un derecho penal de autor, sino simplemente valorar como prueba esos extremos para añadir al resto del material probatorio otros que resultan importantes para determinar en conjunto su responsabilidad. ${ }^{47}$ Así, los indicios de capacidad para delinquir, que también pueden llamarse de oportunidad personal proceden de la compatibilidad de la

\footnotetext{
${ }^{45}$ HERNÁNDEZ ELVIRA, María Jesús, Op. Cit., nota 2, p. 1.

${ }^{46}$ ROSAS YATACO, Jorge; Prueba indiciaria: Doctrina y jurisprudencia nacional, http. www.porticolegal. com. 2014.

47 JAUCHEN, Eduardo M., Op. Cit., nota 15, p 10.
} 
personalidad física y moral con el acto cometido. Por lo que se sabe del conjunto de su carácter, de su conducta pasada, de sus costumbres y disposiciones, se deduce que el acusado era capaz de haber cometido el delito imputado o, inclusive, que fue llevado a ejecutarlo..$^{48}$ Constituye una condición necesaria, pero no suficiente, de la culpabilidad: unas veces proporciona una simple posibilidad y otras, una probabilidad o verosimilitud, pero no certeza. ${ }^{49}$

Indicios sobre el móvil delictivo: Se debe partir de la premisa general de que no existe acto voluntario sin motivo o móvil. [...] de modo que cuando un individuo, se decide a quebrantar la ley y exponerse a una sanción penal, es porque persigue obtener una ventaja, una venganza, o cualquier otro objetivo que se le presenta con tal intensidad que lo lleva a estimar con desdén la eventual sanción. Esta razón predominante es lo que se llama el móvil para delinquir; el cual, como es una condición esencial de todo delito, es de necesaria comprobación, ya por medio de verdaderas pruebas, ya por simples presunciones. El móvil puede considerarse bajo dos aspectos: externo, y entonces es el suceso, la causa, el accidente, que impulsan el ánimo, e interno, siendo entonces el afecto mismo del ánimo que impulsa el delito. De allí que, el autor opta por realizar su objetivo asumiendo el riesgo de las consecuencias. Estos objetivos son los motivos o móviles de los que, cuando el individuo ha obrado voluntariamente, es importante indagar para encontrarle un justificativo al acto delictivo.

Indicios de actitud sospechosa: Generalmente existen comportamientos del sujeto, anteriores o posteriores al hecho, que por su especial singularidad o extravagancia permiten inferir que tiene relación con el delito cometido. ${ }^{50}$ Deducidos de lo que se llama rastros mentales o, en términos más genéricos, de las manifestaciones del individuo, anteriores o posteriores al delito; en pocas palabras, al comportamiento en cuanto revela el estado de ánimo del acusado en relación con el delito; es decir, tanto su malvada intención antes del delito, como su conciencia culpable después de haberlo realizado. ${ }^{51}$

Indicios derivados de una mala justificación: Una vez colectados suficientes elementos probatorios que indiquen a determinado sujeto como autor del hecho delictivo, es menester interrogar al mismo a los fines de que, dando su versión, explique las razones de la existencia de ese material de cargo uno por uno. Su discurso, cualquiera que sea, servirá para integrar la interpretación de aquellas pruebas. Tanto es así que si el inculpado suministra explicaciones satisfactorias y que además se comprueban, los elementos indiciarios existentes pierden eficacia. A la inversa, si sus justificaciones son inaceptables, ambiguas, equívocas, tendientes a eludir una respuesta concreta, deficientes, inventadas o mendaces, todo lo cual también debe comprobarse, ello configurará un refuerzo de aquellos indicios, dando lugar a edificar una plataforma de cargos desfavorable a su situación procesal. La mala justificación se erige así como un complemento indiciario de los demás elementos de prueba. ${ }^{52}$

En extremo opuesto, un sector de la doctrina, ${ }^{53}$ citando a Carnelutti, sostiene que los indicios no se prestan al análisis ni a la clasificación, su función probatoria es meramente accidental y surge por la eventualidad de una relación suya, indefinible a priori con el hecho a probar.

\footnotetext{
${ }^{48}$ ELLERO, Pietro; De la certidumbre en los juicios criminales o tratado de la prueba en materia penal, Buenos Aires: Argentina, Fabian Di Plácido, 1998, p. 103.

49 ROSAS YATACO, Jorge, Op. Cit., nota 46, p. 19

50 JAUCHEN, Eduardo M., Op. Cit, nota 15, p. 10.

${ }^{51}$ Ídem.

52 GORPHE, François. Apreciación judicial de las pruebas, Bogotá: Temis, 1998.

${ }^{53}$ FENOCHIETTO, ARAZI y LEGUIZAMÓN, v, Op. Cit. nota 31.
} 


\section{REGULACIÓN NORMATIVA}

En la Argentina, el derogado Código de Procedimiento Penal en Materia Penal de la Nación, bajo el titulo De las Presunciones o Indicios a tenor de los artículos 357 y 358 respectivamente, definía conceptualmente al instituto y determinaba las condiciones de los mismos, ${ }^{54}$ a los fines de su eficacia como plena prueba, de la siguiente manera: Las presunciones o indicios en el juicio criminal, son las circunstancias y antecedentes, que, teniendo relación con el delito, pueden razonablemente fundar una opinión sobre la existencia de hechos determinados (art. 357).

Seyahian, Daray y Rodríguez, ${ }^{55}$ al comentar dicho artículo, decían: Equipáranse en este artículo los significados de 'presunción' y de 'indicio' pese a su diferencia etimológica. Diremos que indicio es el dato positivo y cierto, mientras que presunción es el efecto probable de aquel. Este es, pues, el conformante de aquella, a la luz de un análisis racional y científico. Se trata, en definitiva, de una relación de causa a efecto.

Sobre el punto, acota Oderigo, el precepto antedicho, se refiere a las presunciones fundadas en circunstancias o antecedentes de hecho, y no a las autorizadas por disposiciones legales o por principios generales del Derecho. ${ }^{56}$

A su vez, el art. 358, establecía:

Para que haya plena prueba por presunciones o indicios es preciso que éstos reúnan las condiciones siguientes: $1^{\circ}$ ) Que el cuerpo de delito conste por medio de prueba directa o inmediata; $2^{\circ}$ ) Que los indicios o presunciones sean varios, reuniendo, cuando menos, el carácter de anteriores al hecho y concomitantes con el mismo; $3^{\circ}$ ) Que se relacionen con el hecho primordial que debe servir de punto de partida para la conclusión que se busca; $4^{\circ}$ ) Que no sean equívocos, es decir, que todos reunidos no puedan conducir a conclusiones diversas; $5^{\circ}$ ) Que sean directos, de modo que conduzcan lógica y naturalmente al hecho de que se trata; $6^{\circ}$ ) Que sean concordantes los unos con los otros, de manera que tengan intima conexión entre sí y se relacionen sin esfuerzo, desde el punto de partida hasta el fin buscado; $7^{\circ}$ ) Que se funden en hechos reales y probados y nunca en otras presunciones o indicios.

Oderigo, ${ }^{57}$ entiende que el Código de Procedimientos en Materia Penal sólo se refiere a los indicios probables, en cuanto requiere solamente que en ellos se pueda fundar una opinión sobre la existencia del hecho (art. 357); y en cuanto exige, para que haya plena prueba presuncional, que los indicios sean varios y concordantes (art. 358 , incs. $2^{\circ}, 4^{\circ}$ y $6^{\circ}$ ). De este modo, concluye afirmando que la certidumbre judicial no se obtendrá, pues, sobre la base de cada uno de los indicios considerados individualmente, ya que siendo éstos sólo probables, admiten la posibilidad de la duda acerca de las causas que los originan. Se obtendrá, en cambio, de su conjunto, en cuanto incidiendo unos sobre otros, eliminen recíprocamente esa

\footnotetext{
${ }^{54}$ De manera idéntica, su similar de la Provincia de Buenos Aires.

55 SEYAHIAN, J. Alberto, DARAY, R. Raúl y RODRÍGUEZ, Alejandro A, Código de procedimiento en materia penal, Comentado, Anotado, p. 30o, Pensamiento Jurídico Editora, Abril de 1979

${ }^{56}$ ODERIGO, Mario A., Op. Cit., nota 21, p. 11.

57 Ídem
} 
posibilidad de duda, de acuerdo a la sana lógica, y en medida suficiente para lograr el íntimo convencimiento.

Corresponde destacar la significación y trascendencia procesal que tuvo el código nacional desde su sanción (1889) hasta su definitiva derogación (1992) en todo el territorio nacional, en virtud de la adhesión formulada por casi todas las provincias al código nacional, adoptado prácticamente a libro cerrado, como código procesal penal en sus respectivas jurisdicciones, muchas de las cuales hasta 1940, cuando adoptan el Código Procesal Penal de Córdoba que introduce la oralidad.

Superada la matriz inquisitorial del modelo del código nacional antes mencionado, en la actualidad, como bien lo señala Maier, el método de la sana critica racional y el sistema de la valoración probatoria dominado por la libre convicción permite claramente el funcionamiento de los indicios, a pesar que la ley procesal, con razón, no se refiera a ellos como medios de prueba.

Aclara sin embargo, que en ocasiones la ley usa la palabra en otro sentido, para indicar el nivel probatorio a alcanzar para determinadas medidas: indicios vehementes de culpabilidad, para autorizar a la policía a aprehender a una persona (CPP Nación, 284, inc. 3, derogado recientemente).

El nuevo Código Procesal Penal de la Nación, ley 27.063, se refiere a los indicios, para determinar la peligrosidad procesal del imputado, pues a los fines de la procedencia de la detención, impone como requisito: si existiere suficientes indicios para sostener razonablemente la procedencia de la prisión preventiva (art.182), y en material probatoria inicial, para promover la investigación preliminar, exige al Fiscal tener indicios de la posible comisión de un delito de acción pública (art.214).

En España, al decir de la Magistrada Hernández Elvira, ${ }^{58}$ la doctrina científica destaca la inexistencia de una detallada regulación procesal en la Ley de Enjuiciamiento Criminal, lo que explica sus dificultades y contradicciones en la realidad jurídica práctica. La Ley de Enjuiciamiento Criminal no contiene ninguna disposición referente a la denominada prueba de indicios. El término indicio, aparece, entre otros, en los arts. 384 y 790.6 LE. Crim., no para señalar una actividad probatoria, sino la imputación racional de un hecho punible a una persona que pueda justificar la adopción de un Auto de procesamiento (art. 384) en el sumario ordinario, o la denegación, si no existieran tales indicios, de la apertura del juicio oral en el procedimiento penal abreviado. Estamos en presencia de un concepto jurídico multívoco, ambiguo e indeterminado. En estos dos preceptos, la ley procesal, utiliza el término indicio dándole una acepción distinta a la que tiene cuando hablamos de prueba de indicios. El indicio del auto de procesamiento y el auto que decreta la apertura de juicio oral, en el procedimiento abreviado, es una conclusión racional que se extrae de una investigación realizada. El juez sospecha de una persona, tras el examen delos hechos que ha investigado y lo declara así, a través de alguna de las resoluciones.

En la misma dirección, en nuestro país, el funcionamiento de los indicios en el proceso tienen una doble operatividad, por un lado: a) como elemento probatorio o de confirmación indirecta, que permite comprobar cómo cierto o probable un hecho anteriormente incierto,

${ }^{58}$ HERNANDEZ ELVIRA, María Jesús, Op. Cit., nota 2, p. 1. 
que incide en el resultado del proceso; y por el otro: b) Como módulo o nivel de convicción para decidir alguna determinada medida que exige dicho recaudo durante el proceso.

El primer supuesto, hace a su propia naturaleza probatoria, una vez lograda la inferencia o conexión del hecho a conocer, se obtiene un nuevo hecho cierto, que es el relevante para el proceso, respecto a cuestiones incidentales y de fondo.

Para algunos autores, ${ }^{59} \mathrm{el}$ indicio introducido legalmente al proceso, produce un conocimiento que puede revestir distintos grados de probabilidad acerca de alguna circunstancia relevante para determinada causa penal, sin embargo aclaran que en el mejor de los casos no supera una probabilidad.

En cambio, Jauchen ${ }^{60}$ atribuye a los indicios fuerza y entidad suficiente para alcanzar la certeza necesaria para dictar una sentencia condenatoria. En tal sentido, afirma:

Dentro de la amplia gama de circunstancias que es menester acreditar, para poder efectuar una acusación y luego la certeza para una condena, en relación a la existencia de un delito y a la participación en él del imputado, su intervención en el hecho es naturalmente la más importante y necesaria. Sin perjuicio, de todos los medios probatorios, este extremo también puede acreditarse mediante elementos indiciarios, aun cuando desde ya cabe poner el acento en que en este caso será preciso: un celo y exigencia mayor que respecto a otras circunstancias, debiendo los indicios ser necesariamente infalibles e irrefutables para sustentar una certeza al respecto.[...]

El segundo supuesto, se vincula estrictamente con la regulación legal que establece como exigencia la existencia de indicios como módulo o nivel de convicción para determinadas medidas durante el proceso penal:

Así, para la detención sin orden judicial, de cualquier persona, se requería indicios vehementes de culpabilidad (v. Art. 284 del Código Procesal Penal de la Nación)

Allanamiento sin orden judicial, cuando se denunciare que personas extrañas han sido vistas mientras se introducían en un local con indicios manifiestos de ir a cometer un delito. (v. Art. 206 CPP de Córdoba y Art. 214 inc. $2^{\circ}$ del CPP de Catamarca)

El nuevo Código Procesal Penal de la Nación, Ley 27.063, establece una disposición similar. (art. $135^{\circ}$ inc. b)

Prisión Preventiva, cuando hubiere vehemente indicios de que el imputado tratará de eludir la acción de la justicia o entorpecer su investigación. (Art. 281 del CPP de Córdoba y 292 CPP de Catamarca)

En la misma dirección, existen otros institutos que si bien no mencionan a los indicios como pauta convicciónal, exigen determinados estados convicciones a los cuales se puede arribar por vía de los indicios, a saber:

La declaración de imputado. En este supuesto, a los fines de la convocatoria para la declaración en tal carácter, la ley utiliza el modulo; cuando hubiere motivos bastante para sospechar, que una persona ha participado en la comisión de un hecho punible lo que a nuestro juicio constituye, el

\footnotetext{
59 AROCENA, Gustavo, y otros, Op. Cit, nota 22, p. 11.
}

${ }^{60}$ JAUCHEN, Eduardo M., Op. Cit, nota 15, p. 10. 
grado mínimo de probabilidad positiva, esto es, escasos o mínimos elementos, en la misma dirección, que bien pueden resultar indicios, para conforman la sospecha que exige la ley. (v.art. 306 del CPP de Córdoba y 305 del CPP de Catamarca)

La detención: También aquí le ley utiliza el modulo: siempre que haya motivos bastantes para sospechar es decir, el mismo recaudo exigido para la citación en calidad de imputado, razón por la cual le cabe las mismas consideraciones del referido instituto. (v. art. 272 del CPP de Córdoba y 284 del CPP de Catamarca).

\section{SISTEMAS DE VALORACIÓN}

Los sistemas de enjuiciamientos establecen expresamente que las pruebas obtenidas durante el proceso serán valoradas con arreglo a la sana crítica racional, lo cual significa apreciar la prueba y fundar la decisión no en el íntimo convencimiento, sino objetivamente en los más genuinos lineamientos que indica la psicología, la experiencia común, las reglas de la lógica y el recto entendimiento humano. ${ }^{61}$

En la Argentina, el nuevo Código Procesal Penal de la Nación, ley.27.063, adopta el mismo sistema, cuando se refiere a la Apreciación de la Prueba, Las pruebas serán valoradas por los jueces, según sus libres convicciones, observando las reglas de la lógica, los conocimientos científicos y las máximas de la experiencias.

Explica Jauchen, que el sistema de valoración va mucho más allá de la denominada sana critica, la cual alude sólo a una de sus características referente al modo de apreciar la prueba, ya que alcanza también al principio de la libertad de la prueba y al principio de la debida fundamentación de la resolución, expresando las razones que motivan la definición, de ahí su denominación global de libre convicción y no solamente sana critica que sólo involucra un aspecto del sistema.

En ese marco, a nuestro juicio, debe entenderse el funcionamiento de los indicios en el proceso penal, pues como dice Maier,62 el método de la sana critica racional y el sistema de valoración probatoria dominada por la libre convicción permite claramente el funcionamiento de los indicios, a pesar que la ley procesal penal, con razón, no se refiera a ellos como medio de prueba.

\footnotetext{
${ }^{61}$ JAUCHEN, Eduardo M, Op. Cit., nota 15, p. 10.

${ }^{62}$ MAIER, Julio B, Op. Cit, nota 13, p. 10. 


\section{LOS ESTADOS CONVICCIONALES DEL PROCESO PENAL}

Un interesante aspecto a repasar, se vincula con los estados convicciones al cual debe arribar los operadores oficiales del sistema, al momento de emitir sus requerimientos, conclusiones y resoluciones, durante las distintas fases del proceso penal.

Los estados psicológicos se ponen de manifiesto en las diversas fases o momentos procesales a los fines de valorar el marco probatorio, y en consecuencia fundamentar las resoluciones judiciales que se dicten en cada caso concreto.

Así podemos diferenciar: la sospecha o probabilidad mínima; la probabilidad; la certeza, certeza negativa y duda.

La sospecha, se conforma con escasos elementos existentes en el proceso, actos iníciales generalmente, con cierta entidad objetiva y peso de seriedad, que son suficientes para alcanzar la mínima probabilidad.

Palacio, ${ }^{63}$ al explicar los grados de la convicción judicial, sostiene lo que él denomina la mínima probabilidad positiva derivada de la existencia de motivos bastantes para sospechar.

La probabilidad, ya no se trata de sospecha, mínima probabilidad, o mera posibilidad, sino como estado psicológico superador, y más próximo a la certeza, en función de los elementos obtenidos, cuando los vinculantes o positivos, superan a los elementos negativos o desvinculantes

Para Maier, ${ }^{64}$ significa un acercamiento plausible al éxito de la acción emprendida, el sujeto estima haberse acercado al resultado buscado, el conocimiento de la verdad, aunque reconoce no haberlo alcanzado totalmente; en otras palabras, no está convencido de esta en posesión de la verdad, pero cree que se ha aproximado bastante a ella.

Agrega el autor citado, que tanto la certeza, como la probabilidad, constituyen estados bipolares, pues la indagación sobre un hecho puede arrojar como resultado que la hipótesis existe, ciertamente, o que no existe, con idéntica certeza, que el hecho es probable o al contrario, improbable

La $d u d a$, al decir de Maier, representa un estado neutro, sin salida posible, ante la imposibilidad de emitir un juicio de certeza o probabilidad, positivo o negativo, sobre la hipótesis objeto de averiguación. Es una posición subjetiva del sujeto cognoscente, que se ubica en al antípoda de la certeza: él reconoce el fracaso absoluto de su intento por conocer la verdad; del fracaso de su acción por conocer, que no le permite afirmar nada cierto o probable sobre el objeto a conocer.

Jauchen, ${ }^{65}$ afirma que es un estado particular del intelecto, según el cual se origina una vacilación pendular entre los motivos que llevan a toma una decisión afirmativa o negativa con relación a una cuestión, debido ello a que los elementos que inspiran esas antagónicas motivaciones no resultan suficientemente explícitos para determina una opción convincente

La Certeza, constituye el estado psicológico del juzgador en cuya virtud se llega a abrigar la plena convicción sobre la existencia o inexistencia del conocimiento buscado. ${ }^{66}$ Quien

\footnotetext{
${ }^{63}$ PALACIO, Lino Enrique, La prueba en el proceso penal, Abeledo Perrot, Argentina, Febrero del $2000, \mathrm{p}$. $14 / 15$.

64 Ídem.

65 JAUCHEN, Eduardo M. Op. Cit, nota 15, p. 10.

${ }^{66}$ PALACIO, Lino Enrique, Op. Cit., nota 63, p. 29.
} 
conoce está convencido de haber alcanzado la finalidad de la acción, esto es de conocer la verdad. ${ }^{67}$

\section{EFICACIA PROBATORIA DE LOS INDICIOS}

En relación a la eficacia probatoria de los indicios, también la doctrina ha señalado algunos condicionamientos:

Así, Maier ${ }^{68}$ explica: para que la afirmación del hecho desconocido tenga valor probatorio cercano a la certeza, son racionales ciertas condiciones. En primer lugar; cabe exigir que el hecho singular verificado, del cual parte el razonamiento, sea afirmado con certeza; en segundo lugar: la regla que permite la inferencia debe ser racional, en el sentido de ser una afirmación de la ciencia, técnica, arte o meramente practica (de la experiencia) tenido por cierta con fundamento; en tercer lugar, la inferencia no debe conducir, con igual rigor racional, a una consecuencia distinta (indicio anfibológico); y en cuarto lugar, los otros medios probatorios u otros indicios, no debe conducir a conclusiones diferentes (prueba en contrario) o, dicho de modo positivo, otros medios de prueba u otros indicios deben también afirmar la conclusión a la que se arriba (prueba compleja).

Hernández Elvira, ${ }^{69}$ señala que para otorgar transcendencia jurídica al indicio es preciso:

1) Que el indicio sea cierto, y no meramente hipotético; a este fin se pregunta si un indicio puede descender de otro indicio; naturalmente, la respuesta no puede ser negativa: es necesario, sin embargo, en estos casos de indicio mediato, observarla máxima cautela y prudentia iuris, a fin de evitar que la reconstrucción de un hecho pase a través de una cadena tal de indicios, que haga perder al proceso de inferencia su máxima capacidad de aproximación a la verdad.

2) Que la deducción del hecho desconocido arrancando del hecho conocido se realice a través de un procedimiento lógico, que se inspire en el máximo rigor, y enla más absoluta corrección;

3) Con la finalidad de conseguir un correcto, riguroso y controlable procedimiento lógico de deducción de un hecho desconocido de otro hecho conocido, se impone, sobre todo, la exigencia de la concordancia de los indicios. Cuando se habla de concordancia de indicios, no se quiere establecer la necesidad de una pluralidad de indicios; la prueba puede derivarse, incluso, de un sólo indicio. Pero es evidente que -aun sin dar prevalencia alguna al dato cuantitativo- cuantos más sean los indicios (naturalmente, ciertos y graves), más fácil es el juicio de probabilidad, puesto que la concordancia sólo se exige en el caso de que la prueba esté encomendada a una pluralidad de indicios, para la observancia de tal requisito es necesario:

a) Que cada uno de los indicios sea valorado autónomamente, a los fines de reconocimiento de las notas de la certidumbre y, en lo posible, de la gravedad; b) Que cada uno de los indicios confluya, juntamente con los otros, a una reconstrucción lógica y unitaria del hecho desconocido. Para esta confluencia, es necesario, que los indicios no estén en contradicción entre sí; Que entre los varios indicios se establezca una coordinación lógica. Es necesario exigir que a la certeza del indicio, se

\footnotetext{
${ }_{67}^{67}$ MAIER, Julio B, Op. Cit, nota 13, p. 10.

68 Ídem.

${ }^{69}$ HERNÁNDEZ ELVIRA, María Jesús, Op. Cit, nota 1, p. 2. 
agregue una tal coordinación lógica entre el indicio y el hecho que se tiene que probar, que excluya la posibilidad de toda otra relación equivalente.

Como se puede ver, en líneas generales, existe coincidencia de la doctrina en relación a las condiciones, requisitos y recaudos que deben reunir los indicios a los fines de su validez y eficacia probatoria en el proceso penal.

\section{ALCANCES DE LA EFICACIA PROBATORIA DE LOS INDICIOS EN EL PROCESO ACUSATORIO}

Nos parece pertinente, como cuestión preliminar, reiterar una vez más la caracterización formulada por la doctrina, respecto al proceso penal acusatorio.

Así, el maestro español, Juan Montero Aroca, ${ }^{70}$ en relación al proceso acusatorio, nos dice: resuelve esencialmente tres cuestiones: no hay proceso sin acusación y esta debe ser formulada por persona ajena al tribunal sentenciador, que no puede condenarse por hechos distintos de los acusados ni a persona distinta de la acusada y que no pueden atribuirse al juzgador poderes de dirección material del proceso que cuestionen su imparcialidad.

Ángela Ledesma, ${ }^{71}$ en interesante distingo entre principio y sistema acusatorio, señala al sistema acusatorio, como modelo omnicomprensivo de una serie de características que se manifiestan en todas las etapas del proceso y con relación a la conformación e integración de sus órganos como un totum revolutum de principios y reglas que tienen sustantividad propia.

A su vez, la referida autora, citando a Jorge Vázquez Rossi, agrega:

El sistema acusatorio se distingue por la meta-diferenciación de la función requirente respecto a la decisoria; igualmente, porque la interposición y contenido de la acción es la que determina el ámbito de la jurisdicción, la que carece de iniciativa y no puede actuar de oficio. Acusador y acusado se encuentran situados en el mismo pie de igualdad, enfrentados a través de un contradictorio en cuyo transcurso aportaran sus postulaciones, frente al tribunal que se sitúa como un tercero imparcial e imperativo y que expresará su decisión conforme al convencimiento alcanzado en las deliberaciones $[\ldots]$

En idéntico sentido, Alvarado Velloso, ${ }^{72}$ cuando define al proceso, como método pacifico de debate dialéctico entre dos partes antagónicas ante un tercero que es impartial, imparcial e independiente.

Establecido el marco referencial del diseño sistémico, cabe ahora reflexionar sobre los alcances de la eficacia probatoria de los indicios en la estructura sistémica del proceso penal acusatorio, sus distintos momentos y etapas que lo componen y en función de los instituto procesales que operan en cada uno de ellos.

En la primera etapa de investigación penal preparatoria, la mayoría de las decisiones trascedentes del Ministerio Público y eventualmente del Juez de Control de Garantías, en el

\footnotetext{
${ }^{70}$ LEDESMA, Ángela Ester, La reforma procesal penal, p.17 y ss., Nova Tesis, Argentina, septiembre de 2005 , p. 17 y ss.

${ }^{71}$ Ídem

72 ALVARADO VELlOSO, Adolfo, Lecciones de Derecho procesal civil, concordado por Gustavo Calvinho, febrero de 2010. La Ley Argentina, p. 176.
} 
marco de su competencia, transitan una brecha convicciónal muy fina, pues giran alrededor de la sospecha o mínima probabilidad, o la probabilidad propiamente dicha.

Así, en los supuestos de: imputación delictiva; declaración de imputado; y detención, la ley requiere motivos bastantes de sospecha; En cambio, para la prisión preventiva y acusación o citación a juicio, se requiere probabilidad.

La franja convicciónal antes mencionada, es terreno fértil para el funcionamiento de los indicios, sobre todo teniendo en cuenta el carácter preparatorio de la investigación penal, donde las decisiones no causan estado, son mutables, revisables y algunas revocable de oficio, pero además el principio in dubio pro reo no funciona en esta etapa procesal, por lo menos en toda su dimensión, lo cual no es un dato menor, porque precisamente la duda funciona a favor de la investigación.

En cambio, en la etapa del juzgamiento propiamente dicho, a la hora de la valoración y deliberación para dictar sentencia, la cuestión cambia radicalmente, pues el funcionamiento de los indicios como fundamento de una sentencia condenatoria, resulta de improbable eficacia autónoma.

En principio cabe destacar que el principio in dubio pro reo, en la etapa del juzgamiento funciona plenamente por imperio legal, lo cual conspira contra la eficacia probatoria de los indicios, pues precisamente se erige como una garantía individual del imputado.

La construcción lógica y mental del indicio, a los fines de alcanzar el nuevo hecho a conocer, pertenece al fuero interno del juzgador, de difícil comprobación y muchas veces se asimila o roza lo que Jorge Montero ${ }^{73}$ denomina la prueba invisible por su arbitrariedad, o como dice Couture, ${ }^{74}$ imaginar la prueba cuando define la sana critica.

En dicho marco, en nuestra opinión, los indicios podrán tener eficacia a los fines de la condena en el proceso penal, en tanto y en cuanto integre el plexo probatorio con el resto de las pruebas directas, de manera tangencial y complementaria, sin incidencia decisiva respecto a la existencia del hecho y la participación del imputado.

En la misma dirección, los indicios, en forma autónoma, no tendrán entidad, ni eficacia como elemento de prueba dirimente, en la fundamentación de una sentencia condenatoria en el proceso penal.

En supuesto hipotético, la simple lógica indica que la prueba indirecta, deforme y dudosa en sus inicios, no puede superar el escudo de garantía que impone el principio del in dubio pro reo en la etapa del juzgamiento.

\section{CONCLUSIONES}

En función de las consideraciones expresadas respecto a la eficacia probatoria de los indicios en el proceso penal acusatorio, surgen las siguientes conclusiones:

$\left.1^{\circ}\right)$ En la investigación penal preparatoria de los sistemas semi acusatorios, la eficacia probatoria de los indicios, resulta plena, en función del carácter preparatorio de la investigación, donde las decisiones no causan estado, son mutables, revisables y en ocasiones revocable de oficio, y cuyo módulo convicciónal gira en un reducido ángulo; de probabilidad mínima o sospecha a probabilidad propiamente dicha, en donde no funciona el in dubio pro reo.

\footnotetext{
${ }^{73}$ MONTERO, Jorge Raúl, ver su tesis doctoral La Prueba Invisible.

${ }^{74}$ COUTURE, Eduardo J, Fundamentos del Derecho procesal civil, Buenos aires, 1958, Argentina, p. 270. 
$2^{\circ}$ ) En la etapa intermedia o de control jurisdiccional de la investigación penal preparatoria, corresponde arribar a la misma conclusión del punto $1^{\circ}$ ).

$3^{\circ}$ ) En la etapa del juzgamiento, el funcionamiento de los indicios como fundamento de una sentencia condenatoria, resulta de improbable eficacia, pues en modo alguno puede superar la aplicación del principio in dubio pro reo, que se erige como una garantía constitucional del imputado.

En razón de ello, los indicios, de manera autónoma, no tendrán entidad, ni eficacia como elemento de prueba dirimente, en la fundamentación de una sentencia condenatoria en el proceso penal.

$4^{\circ}$ ) Sin embargo, podrá tener una eficacia relativa y limitada, en la sentencia condenatoria, en tanto y en cuanto integre el plexo probatorio con el resto de las pruebas directas, y su aporte no se vincule con valor decisivo respecto a la existencia del hecho y la participación del imputado, sino de carácter complementario.

FUENTES

BIBLIOGRÁFICAS

ACUÑA, Ramón, Porfirio, Visita Guiada al Sistema de Enjuiciamiento Penal, Código Procesal Penal de la Provincia de Catamarca, Bibliotex, Agosto de 2010.-

AlVARADO VElloso, Adolfo y ACUÑA, Ramón Porfirio, Lecciones de Derecho Procesal, Adaptado a la Legislación Procesal de la Provincia de Catamarca, Nuevo Enfoque Jurídico, Córdoba, Argentina, 2011.

AROCENA, Gustavo, BALCARCE, Fabián Gustavo y CESANO, José Daniel, Prueba en materia penal, Astrea, Argentina, 2009.

BINDER, Alberto, Código Procesal Penal de la Nación, Infojus, Argentina, 2014.

CAFFERATA NORES, José I, Código Procesal Penal de la Provincia de Córdoba, Lerner, 1992.

La Prueba en el Proceso Penal, Depalma, 1988.-

CHAIA, Rubén A, La prueba en el proceso penal, Hammurabi, 2010.-

CLARIA OLMEDO, Jorge A., Tratado de Derecho Procesal Penal, Rubinzal Culzoni, 2009.

COUTURE, Eduardo J, Fundamentos del Derecho Procesal Civil, Buenos aires, 1958.

DELLEPIANE, Antonio; La nueva teoría de la prueba. Bogotá: Temis, 1994.

DEVIS ECHANDIA, Hernando, Teoría General de la Prueba Judicial, Zavalia, 1981.

ELLERO, Pietro; De la certidumbre en los juicios criminales o tratado de la prueba en materia penal. Buenos Aires: Fabian Di Plácido, 1998. 
FALCON, Enrique M, Lógica y justificación del razonamiento probatorio, dice: rastros, huellas, vestigios y circunstancias" en La prueba en el proceso judicial, Asociación Argentina de Derecho Procesal, Rubinzal Culzoni, 2009.

GORPHE, François, Apreciación Judicial de las Pruebas, Bogotá: Temis, 1998.

GRANILLO FERNÁNDEZ, Héctor M, Juicio por Jurados, Rubinzal Culzoni, Editores, 2013.

HERNÁNDEZ ELVIRA, María Jesús, La Prueba Indiciaria en el Proceso Penal, Jueza en la Comunidad Autónoma de Canarias, www.icalanzarote.com/ Octubre 2010.

JAUCHEN, Eduardo M., Tratado de la Prueba en Material Penal, Rubinzal Culzoni, Marzo de 2004.

KIELMANOVICH, Jorge L, Código Procesal Civil y Comercial de la Nación, Lexis Neris, Abeledo Perrot, Buenos Aires, 2003.

LEDESMA, Ángela Ester, La Reforma Procesal Penal, Nova Tesis, 2005.

LEGUIZAMÓN, Héctor Eduardo, en Las Presunciones Judiciales y Los Indicios, Rubinzal Culzoni, 2006.

MAIER, Julio B, Derecho Procesal Penal Argentino, 1b.Fundamentos, Editorial Hammurabi, 1989. Puerto, 2011.

Derecho Procesal Penal, III, parte general, Actos procesales, Editores Del , Proyecto de Código Procesal Penal de la Nación, Exposición de Motivos, Doctrina Penal, Depalma, 1987.

MANZINI, Vicenzo, Tratado de Derecho procesal penal, traducción española, Buenos Aires, Ed. EJEA, 1952.

MITTERMAIER, Karl, J. A., Tratado de la prueba en material criminal, trad. González del Alba, Madrid, Reus 1906.

MIXÁN MASS, Florencio; La prueba Indiciaria. Trujillo: BLG, 1992.

MONTERO AROCA, Juan, La prueba en el proceso civil, $5^{\text {a }}$ ed. Civitas, Madrid, 2007.

MONTERO, Jorge Raúl, La Prueba Invisible, Tesis Doctoral. UNC.

ODERIGO, MARIO A., Derecho procesal penal, t. I, Buenos Aires, Ed. Depalma, 1973.

PALACIO, Lino Enrique, La Prueba en el Proceso Penal, Abeledo Perrot, Febrero del 2000.

ROSAS YATACO, Jorge; Prueba Indiciaria, Anuario de Derecho Penal, Lima Perú, 2004.

SEYAHIAN, J. Alberto, DARAY, R. Raúl y RODRIGUEZ, Alejandro A, Código de Procedimiento en Materia Penal, Pensamiento Jurídico, Editora, Argentina, Abril de 1979.

VÁSQUEZ ROSSI, Jorge, E; Derecho Procesal Penal, tomo I, Editorial Rubinzal-Culzoni, 1995. 
VÉLEZ MARICONDE, Alfredo, Derecho Procesal Penal, Ediciones Lerner, Argentina, 1968.

ZWANCK, Carlos A., Indicios, en la Enciclopedia Jurídica Omeba, t. XV. 
